\title{
Photodynamic therapy for cancer: Principles
}

\author{
Brian C Wilson PhD
}

BC Wilson. Photodynamic therapy for cancer: Principles. Can J Gastroenterol 2002;16(6):393-396.

The principles of photodynamic therapy (PDT), using drugs (photosensitizers) that are activated by light to become cytotoxic, provide the basis for understanding the current and potential future clinical applications in gastroenterology, general oncology and other specialities. The properties of photosensitizers are key to their biological efficacy, while lasers and optical fibres allow convenient and flexible light delivery for endoscopic use. PDT has several distinct and unique advantages, both as a stand-alone treatment and in combination with other established modalities. The current limitations are also recognized, as is the need for rigorous randomized trials of this emerging technology. The fluorescence of many photosensitizers may be useful, either for (endoscopic) diagnosis or for PDT treatment guidance and monitoring.

Key Words: Cancer; Fluorescence; Laser; Optical fibre; Photodynamic therapy; Photosensitizer

\section{Le traitement photodynamique contre le cancer}

RÉSUMÉ : Les principes du traitement photodynamique (TPD), faisant appel à des médicaments (photosensibilisants) activés par la lumière pour devenir cytotoxiques, permettent d'en comprendre les applications cliniques actuelles et potentielles en gastroentérologie, en oncologie et dans d'autres spécialités. Les propriétés des photosensibilisants sont essentielles à leur efficacité biologique, tandis que les lasers et les fibres optiques permettent de fournir de la lumière avec rapidité et flexibilité en cas d'endoscopie. Le TPD possède plusieurs avantages distincts et uniques, tant à titre de traitement autonome qu'en combinaison avec d'autres modalités établies. Ses limites actuelles sont également reconnues, de même que le besoin de procéder à des essais aléatoires rigoureux au sujet de cette technologie émergente. La fluorescence de nombreux photosensibilisants peut être utile au diagnostic (endoscopique) ou à l'orientation et à la surveillance du TPD.

$\mathrm{P}$ hotodynamic therapy (PDT) is the therapeutic use of drugs (photosensitizers) that are activated by light (1-3). There are three main steps leading from light absorption by the photosensitizer to the therapeutic outcome. Figure 1 shows a typical energy level diagram for photosensitizer activation.

A photon of light of an appropriate wavelength is absorbed by the photosensitizer molecule, raising it to a short-lived (singlet) excited state. The molecule can then undergo internal rearrangement to a longer lived (triplet) state, which exchanges energy with molecular oxygen to produce highly active singlet oxygen $\left({ }^{1} \mathrm{O}_{2}\right)$. The photosen-

This review is based on a presentation made at the 13th International Course on Therapeutic Endoscopy, Toronto, Ontario, October 11 to 14,2000 Department of Medical Biophysics, Ontario Cancer Institute/University of Toronto, Toronto, Ontario

Correspondence and reprints: Dr Brian Wilson, Department of Medical Biophysics, University of Toronto, Ontario Cancer Institute,

Princess Margaret Hospital, 610 University Avenue, Room 7-417, Toronto, Ontario M5G 2M9. Telephone 416-946-2952, fax 416-946-6529,

e-mail wilson@uhnres.utoronto.ca

Received for publication April 23, 2001. Accepted April 23, 2001 


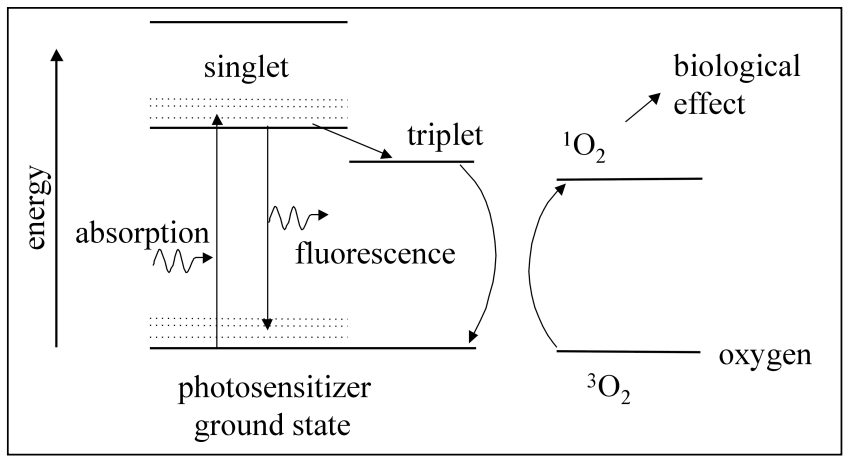

Figure 1) Energy level diagram for photodynamic therapy via generation of singlet oxygen $\left({ }^{1} \mathrm{O}_{2}\right)$

\section{TABLE 1}

Examples of photodynamic therapy drugs

\begin{tabular}{|c|c|c|}
\hline Class & Examples & Commercial drug \\
\hline \multirow[t]{4}{*}{ Porphyrins } & $\mathrm{HpD}$ & $\begin{array}{l}\text { Photofrin* (Axcan } \\
\text { Pharma, Canada) }\end{array}$ \\
\hline & Protoporphyrin IX & Levulan* (DUSA, USA) \\
\hline & BPD-MA & $\begin{array}{c}\text { Vertofrin* (QLT } \\
\text { Phototherapeutics, } \\
\text { Canada) }\end{array}$ \\
\hline & mTHPC & $\begin{array}{c}\text { Foscan* (Biolitec, } \\
\text { Germany) }\end{array}$ \\
\hline Purpurins & Tin etiopurpurin & Purlytin* (Miravant, USA) \\
\hline $\begin{array}{l}\text { Phthalo- } \\
\text { cyanines }\end{array}$ & AIPcSn & - \\
\hline Texafrins & Lutetium texafrin & Lutrin* (Pharmacyclics, USA) \\
\hline Chlorins & Chlorin-e $_{6}$ & NPe6* (Nippon Chemical, Japan) \\
\hline
\end{tabular}

sitizer returns to the ground state, where it may undergo further activation cycles. ${ }^{1} \mathrm{O}_{2}$ is highly reactive and produces the photobiological and clinical response. An alternative decay path for the excited drug is to emit longer wavelength fluorescent light that can be used for tumour detection and localization, or for monitoring the PDT treatment.

In the 1960s, hematoporphyrin derivative was discovered, leading to reports of tumour detection by its fluorescence. In the mid-1970s, tumour eradication was demonstrated in animal models, and the first patient studies were reported shortly thereafter. The first governmental approvals for the use of PDT with hematoporphyrin derivative (in its purified commercial form, Photofrin [Axcan Pharma, Canada]) took place in 1993 in Canada, and this treatment has since been approved in the United States, Europe and Japan for a variety of malignant solid tumours and dysplasias. In the past decade, there have been major advances in new photosensitizers, improved light sources, delivery and dosimetry equipment, and in understanding

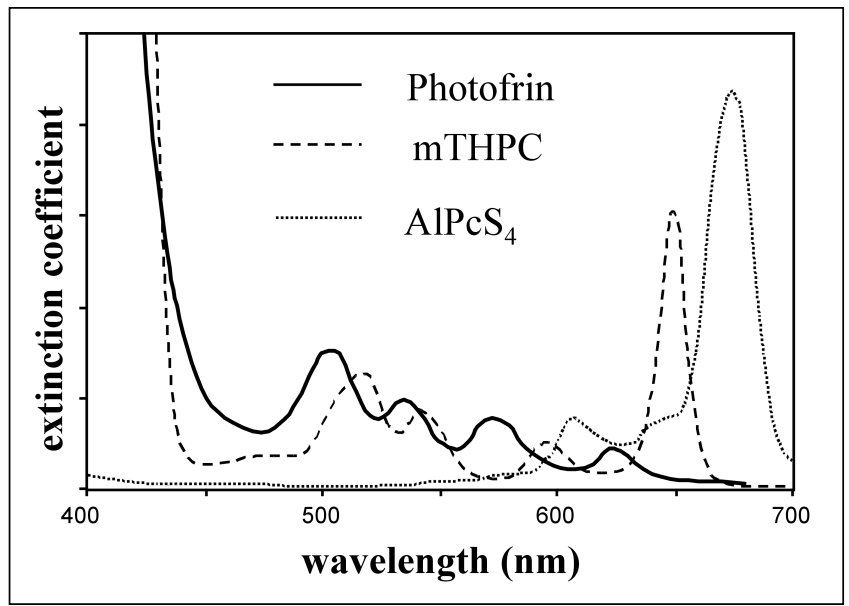

Figure 2) Absorption (extinction) spectra of three photosensitizers. AlPcSn Aluminumchlorosulphonated phthalocyanine; mTHPC Mesotetra(hydroxyphenyl) porphyrin

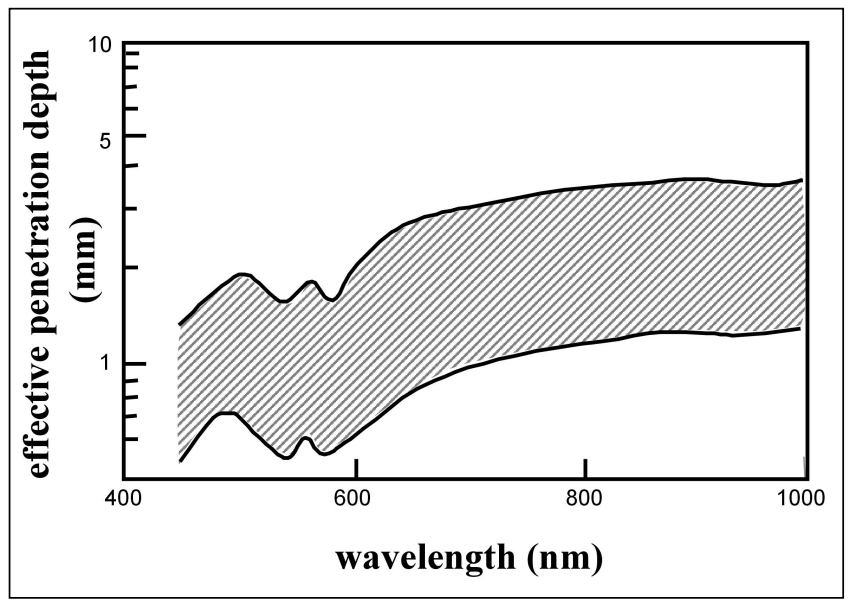

Figure 3) Typical penetration depths of light in tissue ranging from high to low pigmentation, as a function of wavelength

the photophysics, photochemistry and photobiology of PDT (4). The concept of light-activated drug therapy has also been extended to several other medical conditions in addition to solid tumour destruction, and there has been parallel development of fluorescence diagnostics. A partial list of current PDT drugs is given in Table 1.

Except for the 'prodrug' 5-aminolevulinic acid (ALA), these current PDT drugs are all photosensitizers. Administration of ALA increases heme synthesis, the penultimate step of which is the accumulation of a photosensitizer, protoporphyrin IX (PpIX). PpIX tissue selectivity depends on the rates of PpIX synthesis and conversion to heme, while the tissue selectivity of the other photosensitizers relies on their pharmacokinetics and binding. Some drugs also require a delivery vehicle, such as lipid emulsions or liposomes, for in vivo administration, due to poor water solubility. Typically, the tumour to normal host tissue selectivity of photosensitizers is less than about 5:1, but additional selectivity is gained through the targeting of the 
activation light. In most cases, the photosensitizer is administered intravenously (and the dose is expressed in mg of drug/kg body weight). ALA may also be given orally or topically.

One objective for solid tumour therapy has been to increase the photosensitizer activation wavelength to increase the penetration depth of the light in tissue and, hence, the treatment depth or volume. Several absorption spectra are shown in Figure 2, while Figure 3 shows the general wavelength dependence of light penetration in tissue. For very superficial disease, such as Barrett's esophagus, use of short-wavelength light (eg, blue light) may be advantageous. Note that the treatment depth (ie, depth of necrosis) is typically three to five times the light penetration depth.

${ }^{1} \mathrm{O}_{2}$ has a very short lifetime due to its reactivity; therefore, the biochemical damage, primarily lipid peroxidation, occurs very close to the site of photosensitizer localization, usually cell membranes. If the concentration of ${ }^{1} \mathrm{O}_{2}$ is high enough, then cell death occurs, by either necrosis or apoptosis. In tissue, both direct killing of (tumour) cells and damage to blood vessels from killing of endothelial cells, leading to ischemic tissue death, may occur, and immunological effects may also contribute to tumour response.

In most clinical treatments to date, a single drug and light dose have been used. Treatment 'fractionation' has also been investigated, either by repeating the complete drug-light cycle or by using multiple light doses for a single drug administration. Rapid on-off light sequences can increase the tumour response by allowing oxygen to be replenished in cases where the rate of ${ }^{1} \mathrm{O}_{2}$ production exceeds the oxygen perfusion rate in the tissue.

Many photosensitizers are photobleached by light irradiation, ie, the concentration of photoactive drug falls as the drug is destroyed in the photochemical reactions. For some photosensitizers, photobleaching leads to the generation of a photoproduct that may absorb light at a different wavelength and may be photoactive.

PDT involves a combination of drugs and devices. The latter include light sources, light delivery systems and instruments for light, drug and oxygen dosimetry. With most photosensitizers, the delivered light 'dose' (fluence) required is substantial - typically around $100 \mathrm{~J} / \mathrm{cm}^{2}$. This is expressed as the incident energy per unit area of tissue surface. For example, to treat a lesion with a surface area of $10 \mathrm{~cm}^{2}$ in $15 \mathrm{~min}$ requires a total delivered power of about $1 \mathrm{~W}$, within a narrow wavelength band, to overlap with the photosensitizer absorption.

There are two main classes of light source - laser and nonlaser. Lasers can be coupled efficiently to single optical fibres for endoscopic, intraoperative or interstitial light delivery. Recently, compact diode lasers have become available with adequate power for many PDT applications, and are replacing the earlier wavelength-tunable argon dye or potassium titanyl phosphate (KTP)-dye systems. However, each operates at a single wavelength, so that multiple sources are required for use with different drugs. Nonlaser sources, which include wavelength-filtered lamps and light- emitting diodes, generally are used either in 'open beam' configuration or may be coupled into fibre bundles of a few millimetres in diameter.

The transport of the light from the source to the patient is a crucial step in PDT. Endoscopy requires fibre optic delivery, while interstitial activation involves placing optical fibres directly into the tumour. Although a simple cleaved-tip fibre can be used, the power density at the tip can be very high, causing tissue heating. Microlens-tipped fibres may be used for irradiating tissue surfaces, and fibres with scattering tips are available, as either an isotropic point or a line source. The latter come in lengths of about $5 \mathrm{~mm}$ to $10 \mathrm{~cm}$, either rigid or flexible. Multiple fibres can be used interstitially to treat larger tissue volumes, with typical spacings of 5 to $10 \mathrm{~mm}$. With cylindrical diffusing fibres, the light 'dose' may be expressed in terms of light energy delivered per $\mathrm{cm}$ length of fibre, rather than per $\mathrm{cm}^{2}$ of tissue surface area, in cases where the latter is not well defined (eg, for interstitial treatments) or is difficult to measure.

For endoscopic irradiation, microlens and diffusing-tip fibres may be placed via the instrument channel. Specialized irradiators include line fibres incorporated into a cylindrical balloon, which, when inflated, centres the source along the lumen. The balloon surface can be masked to limit the treatment to be only partially circumferential.

The general advantages of PDT for solid tumour therapy are as follow.

- It has double selectivity (drug and light), while either drug or light therapy alone has no effect.

- It can be given before, after or adjuvantly with other standard therapies, including surgery, radiation and chemotherapy, with no known contraindications.

- There is excellent healing of normal host tissue, with preservation of the collagen structure.

- It may be repeated without inducing tumour resistance or normal tissue hypersensitivity.

- It has minimum side effects, except for skin photosensitivity, which requires the patient to take moderate precautions against bright light. With Photofrin, this sensitivity can persist for several weeks, but the effect is greatly reduced with many second-generation drugs, both in severity and in duration.

- By selection of the drug, delivery vehicle and drug-light time interval, different tissue components can be targeted and different mechanisms of action invoked for therapeutic gain.

\section{The current limitations of PDT are as follow.}

- It cannot easily be used for large tumour masses. The penetration of even longer wavelength light limits the effective depth of treatment to typically 5 to $10 \mathrm{~mm}$. Multiple interstitial optical fibres can increase the treated volume. 
- The optimum drug and light doses, and drug-light time interval may vary from patient to patient or lesion to lesion, so that standardized protocols may not achieve the maximum response rates.

- Extensive preclinical and clinical trials are needed for each new photosensitizer and/or indication.

Many PDT photosensitizers are fluorescent (5). Fluorescence measurements can be made in vivo either point by point or by imaging. The target tissue to be treated by PDT can be localized using this fluorescence. The photosensitizer uptake and kinetics can also be determined. Monitoring of photosensitizer photobleaching during or after PDT light irradiation can be used to check that the target tissue has been adequately and uniformly irradiated and/or to assess the fraction of drug bleached.

\section{REFERENCES}

1. Buskard NA, Wilson BC. The use of photodynamic therapy in cancer. Semin Oncol 1994;21(Suppl 15):1-3.

2. Dougherty TJ, Gomer CJ, Henderson BW, et al. Photodynamic therapy. J Natl Cancer Inst 1998;90:889-905.

3. Dougherty TJ. Photodynamic therapy. J Clin Laser Med Surg 1996;14:219-348.

4. Fisher AMR, Murphree AL, Gomer CJ. Clinical and preclinical photodynamic therapy. In: Puliafito CA, ed. Laser Surgery and Medicine. New York: Wiley-Liss, 1996:339-68.

5. Wagnieres GA, Star WM, Wilson BC. In vivo fluorescence spectroscopy and imaging for oncological applications. Photochem Photobiol 1998;68:603-32. 


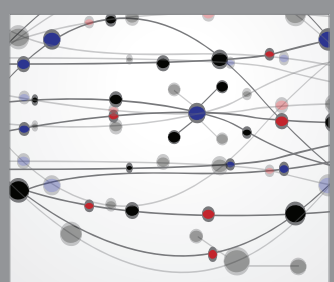

The Scientific World Journal
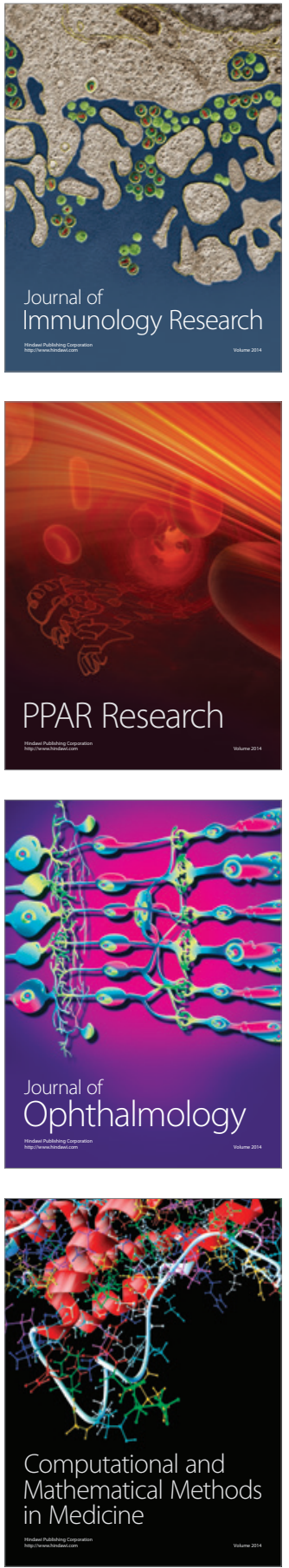

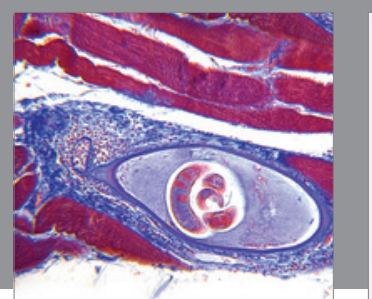

Gastroenterology Research and Practice

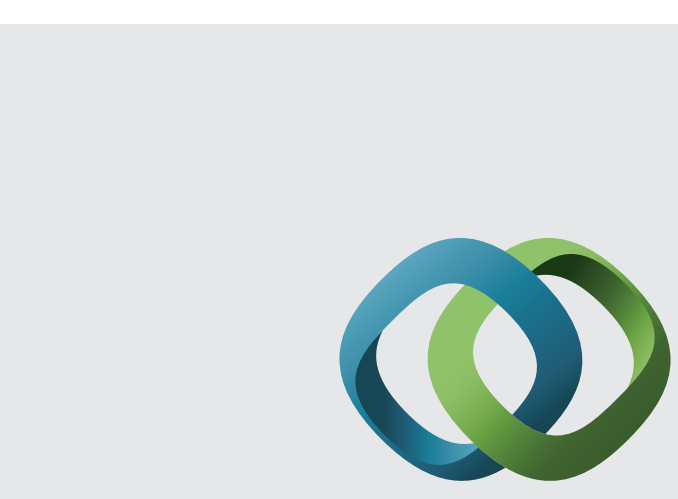

\section{Hindawi}

Submit your manuscripts at

http://www.hindawi.com
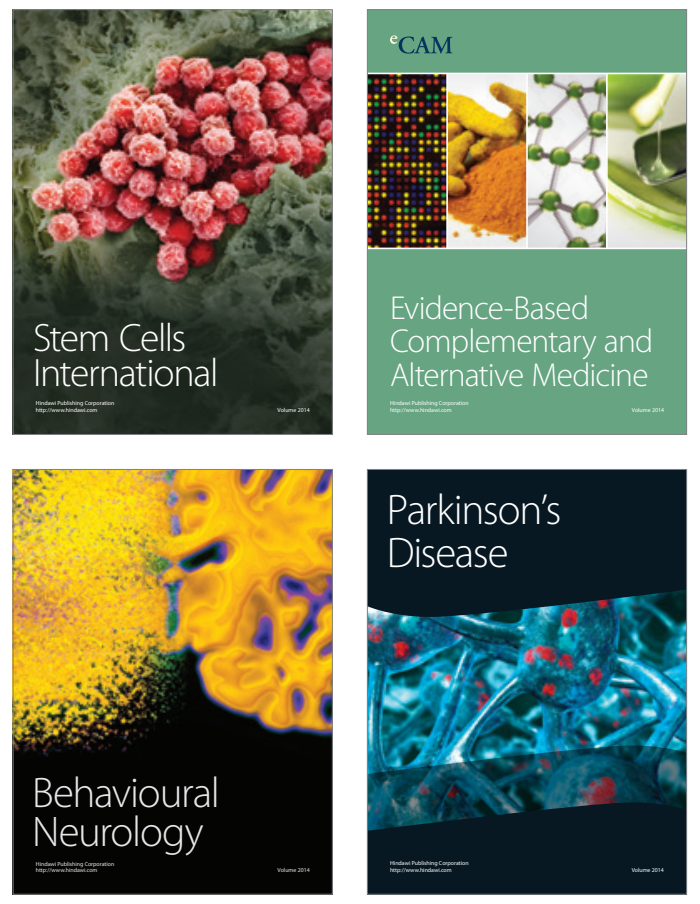
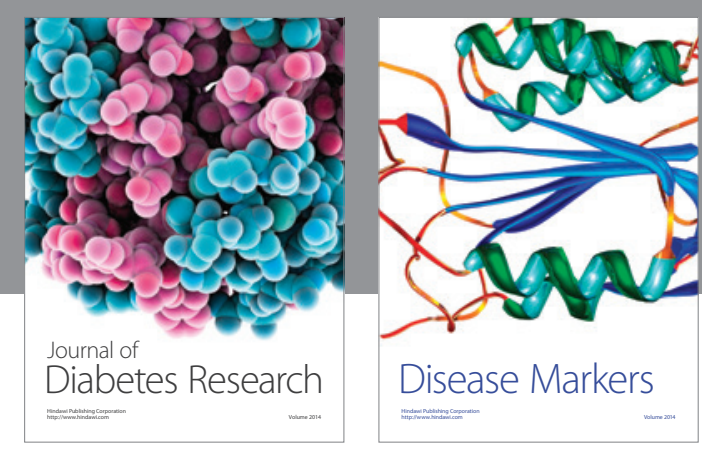

Disease Markers
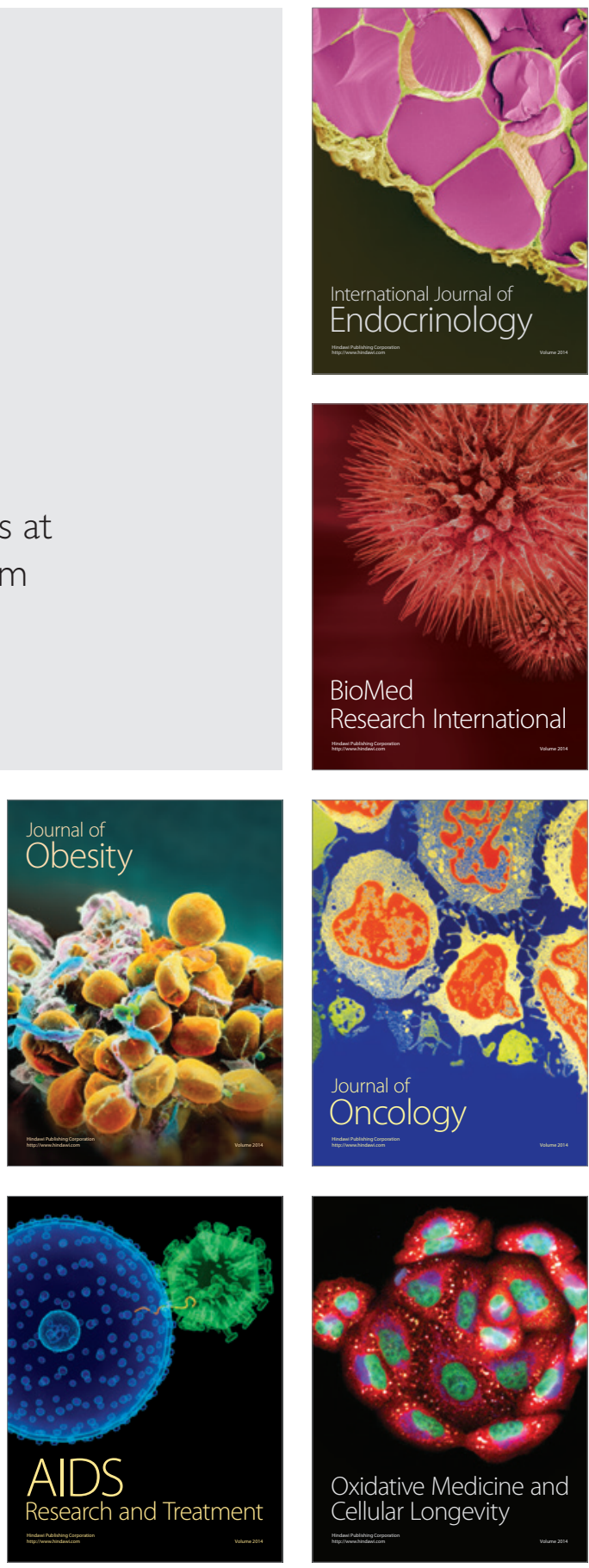